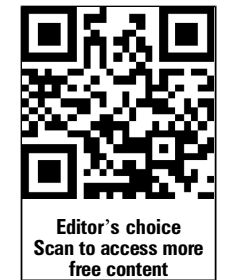

free content

'Department of

Ophthalmology, Changhua Christian Hospital, Changhua, Taiwan

${ }^{2}$ School of Medicine, Chung Shan Medical University, Taichung, Taiwan

${ }^{3}$ Graduate Institute of Statistics and Information Science National Changhua University of Education, Changhua, Taiwan

${ }^{4}$ Institute of Biomedical Sciences, Academia Sinica, Taipei, Taiwan

\section{Correspondence to} Dr I B Lian, Graduate Institute of Statistics and Information Science, National Changhua University of Education, \#1 Jinde Rd,

Changhua 50002, Taiwan maiblian@cc.ncue.edu.tw

Received 1 July 2013 Revised 24 September 2013 Accepted 10 October 2013 Published Online First 29 October 2013
To cite: Chen $\mathrm{S}-\mathrm{N}$ Chen Y-C, Lian I. Br J Ophthalmol 2014;98: 110-114.

\title{
Increased risk of coronary heart disease in male patients with central serous chorioretinopathy: results of a population-based cohort study
}

\author{
San-Ni Chen, ${ }^{1,2}$ Yi-Chiao Chen, ${ }^{3}$ lebin Lian ${ }^{3,4}$
}

\begin{abstract}
Aims To investigate whether patients with central serous chorioretinopathy (CSCR) have increased risk of coronary heart disease (CHD).

Methods Population-based retrospective cohort and case control study. Longitudinal data from the Taiwan National Health Insurance Research Database (20002009) were analysed. The study cohort comprised 835 patients with a diagnosis of CSCR and 4175 age and gender matched patients without CSCR. Kaplan-Meier plots and log-rank tests were used to compare differences in the hazard rates of CHD between the CSCR and non-CSCR cohorts. Stratified Cox proportional hazard models were applied to examine the association between CSCR and CHD, adjusting for potential confounding factors.
\end{abstract}

Results The 5-year CHD cumulative incidence for patients with CSCR was nearly twofold that of the nonCSCR cohort $(6.12 \%$ vs $3.29 \%, p=0.004)$ from the logrank test. The adjusted CHD HR of CSCR versus nonCSCR was 1.61 (95\% Cl 1.12 to $2.30, p=0.009)$ from the Cox model. Specifically, the HR for male patients was $1.72(95 \% \mathrm{Cl} 1.14$ to $2.59, \mathrm{p}=0.010)$ and for female patients it was $1.34(95 \% \mathrm{Cl} 0.64$ to 2.84 , $\mathrm{p}=0.438$ ).

Conclusions Male patients with CSCR had a significantly higher CHD rate than those without CSCR, indicating that CSCR may be a potential risk factor for the development of CHD for men.

\section{INTRODUCTION}

Central serous chorioretinopathy (CSCR) is a maculopathy that is often observed in middle-aged male patients. CSCR typically presents as a serous neurosensory detachment at the posterior pole. Imaging studies on indocyanine green angiography have shown that patients with CSCR have delayed choroidal filling. ${ }^{1}$ Elevated serum plasminogen activator inhibitor 1 (PAI-1) levels were also observed in these patients. $^{2} 3$ These results indicate that an imbalance between coagulation/coagulysis may predispose patients to choroidal vasculopathy in CSCR. Coronary heart disease (CHD), a thrombotic vascular disease of the heart, is a disease that is often observed in men over 45 years of age and in women over 55 years of age. Elevated serum levels of PAI-1 and PAI-1 gene polymorphism were reported to be associated with $\mathrm{CHD} .^{4-7}$ In addition to circulation abnormalities, factors that are associated with increased risk of CSCR and CHD include personality A-type ${ }^{89}$ and male sex. ${ }^{10}$ Although several common predisposing factors are observed in CSCR and CHD, no study has reported on the association between these two diseases. In this study, we aim to study the relationship of CSCR and CHD with a national population-based dataset from Taiwan National Health Insurance (TNHI). This dataset includes de-identified secondary data released for research purposes. This study was approved by the Changhua Christian Hospital Institution Review Board.

\section{MATERIALS AND METHOD}

\section{Data collection and management}

The TNHI programme was initiated in 1995. Since then, medical records of more than $95 \%$ of Taiwan's hospitals contracted with TNHI were included in the database. The coverage rate of the programme increased from $92.4 \%$ in 1995 to $>96 \%$ in 2000 . About $>98 \%$ of the population in Taiwan were covered by health insurance after the inclusion of the military forces in 2001.

One million residents of Taiwan who were enrolled in TNHI in 2005 were randomly selected by the National Health Research Institute (NHRI). Their healthcare records were analysed in this study. The sample comprised almost $4 \%$ of Taiwan's population, and was re-sampled by NHRI to confirm its structural resemblance to the general population with respect to gender and age.

Demographic variables such as age, gender, diagnosis date and monthly income were also itemised. All cases in the database were counted only once. Before analysis, the temporal consistency between birth dates, diagnosis dates and clinical visits of each patient were checked to ensure data accuracy.

\section{Statistical analysis}

A sample of 597063 adults aged from 20 to 64 in 2000 who were selected from the TNHI database were considered in this study. The CSCR cohort consisted of those who had been diagnosed with CSCR, and the remainder made up the non-CSCR cohort. Only patients with at least two clinical visits classified as ICD code 362.41 were included in the CSCR cohort to ensure the accuracy of diagnosis. Patients with preexisting CHD (prior to CSCR diagnosis) were excluded. After further excluding those with degenerative myopia, uveitis, diabetic retinopathy, branch retinal vein occlusion, age-related macular degeneration, Harada disease, malignant neoplasm of the choroid, and those who had suffered from toxaemia during pregnancy, 815 patients with CSCR were included in the analysis.

Each patient with CSCR was matched with five patients who were randomly selected from the non-CSCR cohort to form a matched control group. Each patient with CSCR and corresponding 
control patients were followed from CSCR diagnosis until either CHD diagnosis or censorship (ie, no longer included in the TNHI programme for any reason or reached the end of 2009). Kaplan-Meier plots and log-rank tests were used to compare the CHD-free survival rate between CSCR and non-CSCR cohorts. Stratified Cox proportional hazard models (with matched age and gender) were fitted by adjusting for the patient's monthly income and diabetes mellitus (DM), hypertension, hyperlipidaemia and steroid usage to further study the effects of CSCR on CHD risk. Steroid usage is a binary variable and a user was defined as a person who had at least three clinical visits with prescription of glucocorticoids within the 12 months prior to any diagnosis of CHD. Note that for the survival analyses, patients with CHD diagnosis prior to CSCR diagnosis were excluded, using the diagnosis date of CSCR as the baseline for CSCR and its matched control.

We treated all 815 patients with CSCR as the case group, and the 4075 patients without CSCR as the control group. We used conditional /logistic regression to examine if preexisting $\mathrm{CHD}$ is a risk factor of CSCR.

Similar to CSCR, the diagnoses of CHD, DM and hypertension were confirmed by at least two clinical visits. Data management and analyses were carried out using Statistical Analysis System (SAS) V.9.3.

\section{RESULTS}

Among the 815 patients with CSCR, 603 were men and 212 were women. Table 1 presents the distribution of demographic characteristics and selected disorders such as hypertension, DM, hyperlipidaemia and CHD for the CSCR and the comparison groups. A higher monthly income was associated with higher risk of CSCR $(p=0.007)$. Steroid usage was also highly associated with CSCR $(p<0.0001)$. The CSCR and the control cohorts shared the same age-gender distribution because the selection of the comparison cohort was matched by age and gender.

After excluding 41 patients with CHD diagnosis prior to CSCR diagnosis (along with fivefold corresponding matched controls), 774 patients with CSCR and 3911 without CSCR were used in the survival analysis, and 83 and 286, respectively, had CHD diagnosis during the follow-up. The median, range and inter-quartile range of the follow-up time for the CSCR group were 4.7, 10 and 4.5 years, and those for the non-CSCR group were 4.7, 10 and 4.6 years, respectively.

Figure 1 presents the results of the Kaplan-Meier analysis of CHD. The unadjusted 5-year CHD rate for patients with CSCR was nearly two times greater than that for those without CSCR $(6.25 \%$ vs $3.24 \%)$ with a $p$ value of 0.002 from the log-rank test.

Table 2 illustrates the overall adjusted hazard rate ratios (HRRs) of CHD, which were obtained from age-gender stratified Cox's proportional hazards regressions. After adjusting for the patient's monthly income, urbanisation level, steroid usage, status of disease such as DM, hypertension and hyperlipidaemia, the overall adjusted CHD HRR for patients with CSCR versus those without CSCR was 1.61 (95\% CI 1.12 to 2.30 , $\mathrm{p}=0.009)$. The age-gender-specific Cox models in table 3 further indicate that the risk of $\mathrm{CHD}$ was higher for male patients with CSCR with an adjusted CHD HRR of 1.72 (95\% CI 1.14 to $2.59, \mathrm{p}=0.01$ ) than for male patients without CSCR. By contrast, the risk of CHD for female patients was not significant. More specifically, the adjusted CHD HRR for younger male patients with CSCR versus those without CSCR (age <40) was $2.66(95 \%$ CI 1.02 to $6.91, p=0.045)$, whereas for older male patients the results were less significant $(p=0.06)$.
Table 1 Distribution of demographic characteristics, hypertension, steroid usage, and CHD of patients with CSCR and non-CSCR groups

\begin{tabular}{|c|c|c|c|c|c|}
\hline \multirow[b]{2}{*}{ Variable } & \multicolumn{2}{|c|}{$\operatorname{CSCR}(n=815)$} & \multicolumn{2}{|l|}{$\begin{array}{l}\text { Non-CSCR } \\
(n=4075)\end{array}$} & \multirow[b]{2}{*}{$\mathrm{p}$ Value } \\
\hline & Total no & $\%$ & Total no & $\%$ & \\
\hline Age, mean (SD) & $41.48(8.64$ & & $41.47(8.64$ & & 0.98 \\
\hline Gender & & & & & 1 \\
\hline Male & 603 & 73.99 & 3015 & 73.99 & \\
\hline Female & 212 & 26.01 & 1060 & 26.01 & \\
\hline Monthly income (NT\$*) & & & & & 0.007 \\
\hline$\leq 20000$ & 263 & 32.27 & 1548 & 37.99 & \\
\hline 20001-30000 & 214 & 26.26 & 1010 & 24.79 & \\
\hline$\geq 30001$ & 338 & 41.47 & 1517 & 37.23 & \\
\hline Urbanisation level & & & & & 0.10 \\
\hline Urban & 370 & 45.40 & 1978 & 48.54 & \\
\hline Rural & 445 & 54.60 & 2097 & 51.46 & \\
\hline Hypertensiont & & & & & 0.15 \\
\hline Yes & 93 & 11.41 & 398 & 9.77 & \\
\hline No & 722 & 88.59 & 3677 & 90.23 & \\
\hline DMt & & & & & 0.80 \\
\hline Yes & 41 & 5.03 & 214 & 5.25 & \\
\hline No & 774 & 94.97 & 3861 & 94.75 & \\
\hline Hyperlipidaemia† & & & & & 0.59 \\
\hline Yes & 37 & 4.54 & 203 & 4.98 & \\
\hline No & 778 & 95.46 & 3872 & 95.02 & \\
\hline CHD† & & & & & 0.19 \\
\hline Yes & 41 & 5.03 & 164 & 4.02 & \\
\hline No & 774 & 94.97 & 3911 & 95.98 & \\
\hline Corticosteroid usage & & & & & $<0.0001$ \\
\hline Yes & 104 & 12.76 & 328 & 8.05 & \\
\hline No & 711 & 87.24 & 3747 & 91.95 & \\
\hline
\end{tabular}

The result of conditional logistic regression in table 4 does not suggest that pre-existing CHD was a risk factor for CSCR after adjusting for income, urbanisation level, steroid usage, DM, hypertension and hyperlipidaemia.

Each patient in the control group was randomly sampled from the non-CSCR cohort who matched the age and gender of a patient from the study cohort. We repeated this sampling scheme twice to confirm the results. The results from both trials were very similar to those reported above.

\section{DISCUSSION}

The correlation of CSCR and systemic cardiovascular disease has been reported in various studies. Tittl et $a l^{11}$ reported that CSCR is a risk factor for hypertension. However, Kitzmann et $a l^{12}$ claimed that hypertension is not a significant risk factor for CSCR. Haimovici et $a l^{13}$ reported that uncontrolled systemic hypertension, instead of hypertension, is a risk factor for CSCR. An increased incidence of stroke has been reported in patients with CSCR by Tsai et al. ${ }^{14}$ In their study, after adjusting for other confounding factors, CSCR is reported to be an independent risk factor for stroke. Tittl et $a l^{11}$ studied the correlation between CHD and CSCR, in which logistic regression analysis results revealed that $\mathrm{CHD}$ is not a statistically significant risk factor for CSCR. The results from the present study are in 
Figure 1 Coronary heart disease (CHD)-free survival rates for patients with central serous chorioretinopathy (CSCR) and those without CSCR, 2000-2009. The log-rank test result indicates a significant difference in CHD with $p$ value $=0.002$. The follow-up of each patient started from the time of CSCR diagnosis, and 83 from the CSCR cohort and 286 from the non-CSCR cohort had CHD diagnosis during the follow-up.

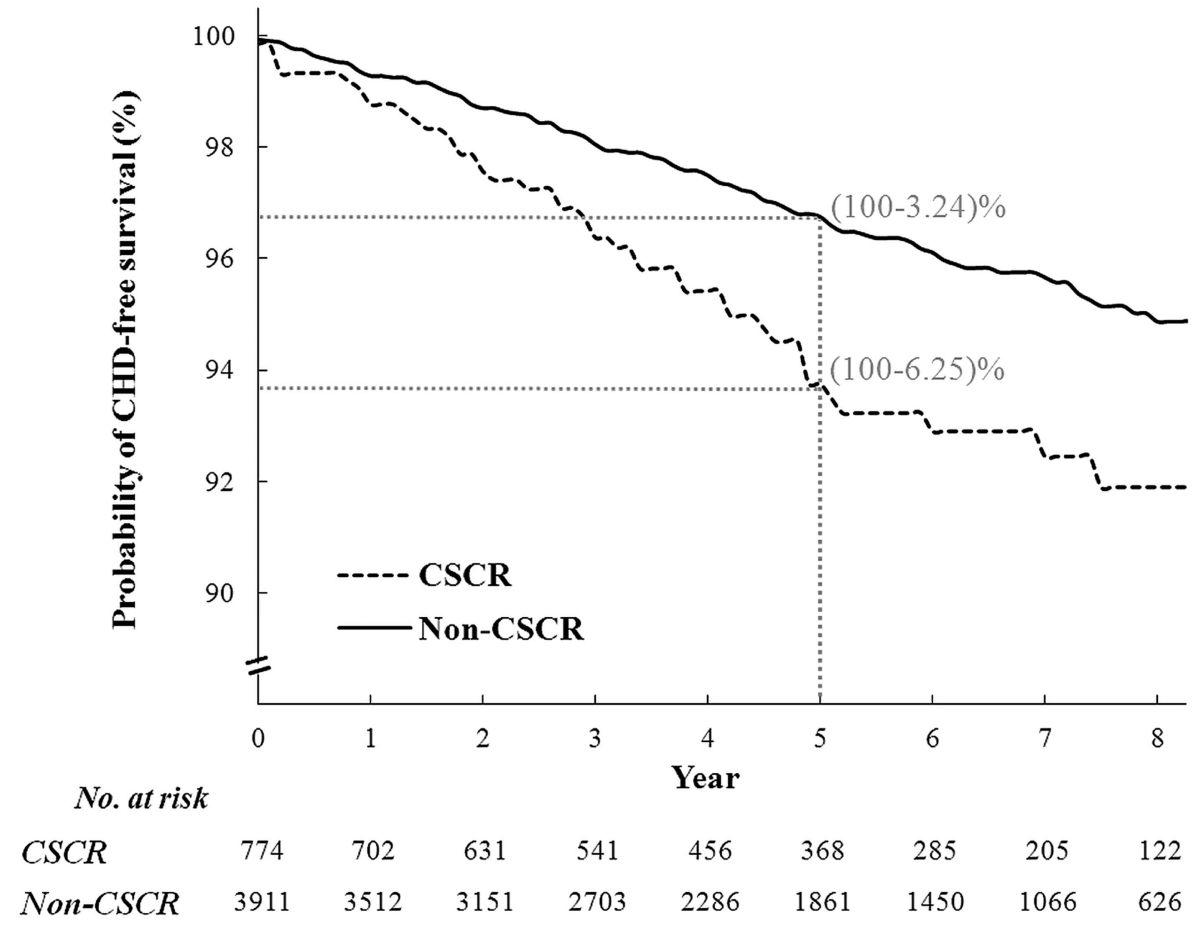

accordance with their results. However, for the reversed causal relation, the Cox regression analysis results in our study show that after adjusting for DM, hypertension and hyperlipidaemia,

Table 2 CHD hazard rate ratio (HRR) for patients with CSCR versus those without CSCR

\begin{tabular}{|c|c|c|c|c|}
\hline Variable & $\begin{array}{l}\text { Estimated } \\
\text { coefficient }\end{array}$ & SE & p Value & HRR $(95 \% \mathrm{Cl})$ \\
\hline \multicolumn{5}{|l|}{ Urbanisation level } \\
\hline Urban & 0.031 & 0.160 & 0.85 & $1.03(0.75$ to 1.41$)$ \\
\hline Rural & - & - & - & - \\
\hline \multicolumn{5}{|c|}{ Monthly income (NT\$*) } \\
\hline$\leq 20000$ & - & - & - & - \\
\hline $20001-30000$ & -0.084 & 0.219 & 0.70 & 0.92 (0.60 to 1.41$)$ \\
\hline$\geq 30001$ & 0.120 & 0.186 & 0.52 & $1.13(0.78$ to 1.62$)$ \\
\hline \multicolumn{5}{|l|}{ Hypertension } \\
\hline Yes & 1.366 & 0.173 & $<0.0001$ & $3.92(2.79$ to 5.50$)$ \\
\hline No & - & - & - & - \\
\hline \multicolumn{5}{|l|}{ DM } \\
\hline Yes & 0.068 & 0.211 & 0.75 & 1.07 (0.71 to 1.62$)$ \\
\hline No & - & - & - & - \\
\hline \multicolumn{5}{|l|}{ Hyperlipidaemia } \\
\hline Yes & 0.897 & 0.189 & $<0.0001$ & 2.45 (1.69 to 3.55$)$ \\
\hline No & - & - & - & - \\
\hline \multicolumn{5}{|c|}{ Corticosteroid usage } \\
\hline Yes & 0.475 & 0.214 & 0.026 & 1.61 (1.06 to 2.45 ) \\
\hline No & - & - & - & - \\
\hline \multicolumn{5}{|l|}{ CSCR } \\
\hline Yes & 0.474 & 0.182 & 0.009 & 1.61 (1.12 to 2.30$)$ \\
\hline No & - & - & - & - \\
\hline \multicolumn{5}{|c|}{$\begin{array}{l}\text { Bold values indicate statistically significant } p \text { values. } \\
\text { The results were obtained from an age-gender stratified Cox model and adjusted for } \\
\text { urbanisation level, income, hypertension, DM, hyperlipidaemia and steroid usage. } \\
\text { After excluding pre-existing CHD, } 774 \text { patients with CSCR and } 3870 \text { patients without } \\
\text { CSCR were used in the analysis. } \\
\text { *NT\$: new Taiwan dollar. } \\
\text { CHD, coronary heart disease; CSCR, central serous chorioretinopathy; DM, diabetes } \\
\text { mellitus. }\end{array}$} \\
\hline
\end{tabular}

CSCR is potentially an independent risk factor for CHD development $(p=0.009$, HRR 1.61). The 5-year cumulative incidence is $6.25 \%$ for the CSCR group and $3.24 \%$ for the comparison group. For age and gender specific analyses, male patients under 40 years of age have the highest HRR. The adjusted risk of CHD development is 2.66 times greater than that of the comparison group $(p=0.045)$.

The underlying mechanism for the association of CHD and CSCR may be as follows. First, coagulation/coagulysis imbalance in CHD and CSCR may be pathogenic for both diseases. Abnormal fibrin deposition ${ }^{15-17}$ and elevated serum level of PAI- $1^{4-7}$ were reported in patients with CHD. Systemic aspirin is a commonly used medication to prevent ischaemic heart attack. However, choroidal circulation abnormality is now considered one of the most possible contributing factors in CSCR. ${ }^{1}{ }^{18} 19$ Delayed choroidal arterial filling and venous congestion in indocyanine green angiography ${ }^{1}$ and subretinal fibrin deposition in several patients with variant $\mathrm{CSCR}^{20}$ suggest that coagulation Studies that have demonstrated that systemic aspirin is effective in treating CSCR further support the hypothesis. ${ }^{21} 22$ Second, personality A-type, which is prevalent in patients with CHD and CSCR, may be a common predisposing factor for both diseases. The sympatho-adrenal system or other endocrine cascades such as increased serum cortisol level triggered by emotional stress ${ }^{23-28}$ may be pathogenic for both diseases.

Only male patients have increased risk of CHD because the male sex is a risk factor for $\mathrm{CHD}$ and male patients tend to have CHD onset at an earlier age compared with their female counterparts. ${ }^{10}$ Male patients under 40 years of age have a higher risk compared with the age and sex controlled group. This result was observed because younger patients, age, hypertension, DM, hyperlipidaemia and other confounding factors of $\mathrm{CHD}$ are less prevalent and may be of less importance in CHD pathogenesis. Thus, CSCR may stand out as a more prominent risk factor. Moreover, the circulation abnormality underlying CSCR may be caused by premature atherosclerosis, which may induce premature CHD in those patients. abnormality might have an important pathogenic role in CSCR. 
Table 3 Age and gender specific CHD hazard rate ratio (HRR) for patients with CSCR versus those without CSCR

\begin{tabular}{|c|c|c|c|c|c|c|c|}
\hline Age & CSCR & $\mathrm{n}$ & No. of CHD & Estimated coefficient & SE & $\mathrm{p}$ Value & HRR $(95 \% \mathrm{Cl})$ \\
\hline \multicolumn{8}{|l|}{ Men } \\
\hline$<40$ & $\begin{array}{l}\text { Yes } \\
\text { No }\end{array}$ & $\begin{array}{r}242 \\
1240\end{array}$ & $\begin{array}{r}8 \\
11\end{array}$ & $\begin{array}{l}0.977 \\
-\end{array}$ & $\begin{array}{l}0.488 \\
-\end{array}$ & $\begin{array}{l}0.045 \\
-\end{array}$ & $\begin{array}{l}2.66 \text { (1.02 to } 6.91) \\
-\end{array}$ \\
\hline$\geq 40$ & $\begin{array}{l}\text { Yes } \\
\text { No }\end{array}$ & $\begin{array}{r}301 \\
1562\end{array}$ & $\begin{array}{l}25 \\
78\end{array}$ & $\begin{array}{l}0.444 \\
-\end{array}$ & $\begin{array}{l}0.236 \\
-\end{array}$ & $\begin{array}{l}0.060 \\
-\end{array}$ & $\begin{array}{l}1.56 \text { (0.98 to } 2.48) \\
-\end{array}$ \\
\hline Overall & $\begin{array}{l}\text { Yes } \\
\text { No }\end{array}$ & $\begin{array}{r}543 \\
2802\end{array}$ & $\begin{array}{l}33 \\
89\end{array}$ & $\begin{array}{l}0.542 \\
-\end{array}$ & $\begin{array}{l}0.209 \\
-\end{array}$ & $\begin{array}{l}0.010 \\
-\end{array}$ & $\begin{array}{l}1.72 \text { (1.14 to } 2.59) \\
-\end{array}$ \\
\hline \multicolumn{8}{|l|}{ Women } \\
\hline$<40$ & $\begin{array}{l}\text { Yes } \\
\text { No }\end{array}$ & $\begin{array}{l}105 \\
539\end{array}$ & $\begin{array}{l}2 \\
6\end{array}$ & $\begin{array}{l}0.275 \\
-\end{array}$ & $\begin{array}{l}0.893 \\
-\end{array}$ & $\begin{array}{l}0.76 \\
-\end{array}$ & $\begin{array}{l}1.32 \text { (0.23 to } 7.58) \\
-\end{array}$ \\
\hline$\geq 40$ & $\begin{array}{l}\text { Yes } \\
\text { No }\end{array}$ & $\begin{array}{r}84 \\
448\end{array}$ & $\begin{array}{r}7 \\
27\end{array}$ & $\begin{array}{l}0.251 \\
-\end{array}$ & $\begin{array}{l}0.430 \\
-\end{array}$ & $\begin{array}{l}0.56 \\
-\end{array}$ & $\begin{array}{l}1.29 \text { (0.55 to } 2.98) \\
-\end{array}$ \\
\hline Overall & $\begin{array}{l}\text { Yes } \\
\text { No }\end{array}$ & $\begin{array}{l}189 \\
987\end{array}$ & $\begin{array}{r}9 \\
33\end{array}$ & $\begin{array}{l}0.296 \\
-\end{array}$ & $\begin{array}{l}0.381 \\
-\end{array}$ & $\begin{array}{l}0.44 \\
-\end{array}$ & $\begin{array}{l}1.34 \text { (0.64 to } 2.84) \\
-\end{array}$ \\
\hline
\end{tabular}

Bold values indicate statistically significant $p$ values.

The results were obtained from Cox models and adjusted for urbanisation level, income, hypertension, DM, hyperlipidaemia and steroid usage.

CHD, coronary heart disease; CSCR, central serous chorioretinopathy; DM, diabetes mellitus.

The main values of this study are as follows. First, the study is based on a nationwide and population-based dataset, which covers over $98 \%$ of the population. Thus, selection bias in referral centres is removed. Second, this study is a cohort study with maximum longitudinal data of 10 years. Thus, this study is preferred to a cross-sectional study in monitoring CHD incidence in CSCR and comparison cohorts. Third, the level of urbanisation,

Table 4 ORs of CSCR, which were estimated from conditional logistic regression of CSCR status on CHD and adjusted for urbanisation level, income, hypertension, DM, hyperlipidaemia and steroid usage

\begin{tabular}{|c|c|c|c|c|}
\hline Variable & $\begin{array}{l}\text { Estimated } \\
\text { coefficient }\end{array}$ & SE & p Value & OR $(95 \% \mathrm{Cl})$ \\
\hline \multicolumn{5}{|l|}{ Urbanisation level } \\
\hline Urban & -0.130 & 0.079 & 0.10 & 0.88 (0.75 to 1.03$)$ \\
\hline Rural & - & - & - & - \\
\hline \multicolumn{5}{|c|}{ Monthly income (NT\$*) } \\
\hline$\leq 20000$ & - & - & - & - \\
\hline $20001-30000$ & 0.206 & 0.103 & 0.046 & 1.23 (1.00 to 1.50$)$ \\
\hline$\geq 30001$ & 0.295 & 0.092 & 0.001 & 1.34 (1.12 to 1.61$)$ \\
\hline \multicolumn{5}{|l|}{ Hypertension } \\
\hline Yes & 0.162 & 0.110 & 0.14 & $1.18(0.95$ to 1.46$)$ \\
\hline No & - & - & - & - \\
\hline \multicolumn{5}{|l|}{ DM } \\
\hline Yes & -0.180 & 0.150 & 0.23 & $0.84(0.62$ to 1.12$)$ \\
\hline No & - & - & - & - \\
\hline \multicolumn{5}{|l|}{ Hyperlipidaemia } \\
\hline Yes & 0.050 & 0.138 & 0.72 & $1.05(0.80$ to 1.38$)$ \\
\hline No & - & - & - & - \\
\hline \multicolumn{5}{|c|}{ Corticosteroid usage } \\
\hline Yes & 0.512 & 0.122 & $<0.0001$ & 1.67 (1.31 to 2.12$)$ \\
\hline No & - & - & - & - \\
\hline \multicolumn{5}{|l|}{ Pre-existing CHD } \\
\hline Yes & 0.213 & 0.193 & 0.27 & $1.24(0.85$ to 1.81$)$ \\
\hline No & - & - & - & - \\
\hline \multicolumn{5}{|c|}{$\begin{array}{l}\text { A total of } 41 / 815 \text { patients with CSCR and } 164 / 4075 \text { controls had pre-existing CHD. } \\
{ }^{*} \mathrm{NT} \text { : new Taiwan dollar. } \\
\text { CHD, coronary heart disease; CSCR, central serous chorioretinopathy; DM, diabetes } \\
\text { mellitus. }\end{array}$} \\
\hline
\end{tabular}

monthly income, DM, hypertension and hyperlipidaemia were taken into account as compounding factors to adjust the CHD HRR in patients with CSCR. Thus, our results are more reliable.

However, inherent limitations in the study include the following. First, interpretation of imaging studies was not possible using the insurance-claim data source; thus, diagnosis was less accurate. To mitigate this problem, we only recruited cases diagnosed with CSCR codes on at least two visits during the study period to lessen the chance of misdiagnosis. However, restricting the recruited cases may also result in incomplete recruitment. Second, personal information known to contribute to $\mathrm{CHD}$, such as body mass index and smoking habit, were not available from the administrative database, and this could have compromised our results. Nonetheless, we were able to archive the clinical information of smoking abstention in the CSCR and control groups. Among the patients with CSCR, 2.71\% (21/774) had a clinical visit for smoking abstention, while the proportion for the non-CSCR cohort was $3.50 \%(137 / 3911)$. $\chi^{2}$ test shows no significance between the proportions $(\mathrm{p}=0.266)$. Third, several patients with CSCR may not seek help if they have mild clinical symptoms and if the duration is short. However, this factor would be of little significance because patients in Taiwan can visit an ophthalmologist anytime without a referral from a general practitioner for a limited amount of money (between US\$5 and 15).

In conclusion, this study demonstrates that patients with CSCR have an increased risk of CHD development. Patients with CSCR should be educated about this possibility. Changes in the patient's lifestyle may help prevent CHD development. A routine survey of electrocardiogram and other screening tests for CHD should be performed.

Contributors Conception and design: S-NC. Analysis and interpretation of data: Y-CC. Drafting the article: IBL, S-NC. Revising it critically for important intellectual content: IBL and Y-CC. Final approval: S-NC.

Competing interests None.

Provenance and peer review Not commissioned; externally peer reviewed.

Data sharing statement Our study is based on the National Health Insurance Research Database provided by the Bureau of National Health Insurance of Taiwan.

\section{REFERENCES}

1 Kitaya N, Nagaoka T, Hikichi T, et al. Features of abnormal choroidal circulation in central serous chorioretinopathy. Br J Ophthalmol 2003:87:709-12. 
2 Yamada R, Yamada S, Ishii A, et al. Evaluation of tissue plasminogen activator and plasminogen activator inhibitor-1 in blood obtained from patients of idiopathic central serous chorioretinopathy. Nippon Ganka Gakkai Zasshi 1993;97:955-60.

3 lijima H, lida T, Murayama K, et al. Plasminogen inhibitor 1 in central serous chorioretinopathy. Am J Ophthalmol 1999;127:477.

4 Wiman V. Plasminogen activator inhibitor 1 in thrombotic disease. Curr Opin Hematol 1996:3:372-8

5 Festa A, D'Agostino R Jr, Rich SS, et al. Promoter (4G/5G) plasminogen activator inhibitor-1 genotype and plasminogen activator inhibitor-1 levels in blacks, Hispanics, and non-Hispanic whites: the Insulin Resistance Atherosclerosis Study. Circulation 2003;107:2422-7.

6 Z Guan L, Ji X, Wang J, et al. Association of plasminogen activator inhibitor-1 gene $4 \mathrm{G} / 5 \mathrm{G}$ polymorphism and coronary heart disease in Chinese patients. Zhonghua $\mathrm{Yi}_{\mathrm{i}}$ Xue Yi Chuan Xue Za Zhi 2002;19:393-6.

7 Bottiger C, Koch W, Lahn C, et al. 4G/5G polymorphism of the plasminogen activator inhibitor-1 gene and risk of restenosis after coronary artery stenting. Am Heart J 2003;146:855-61.

8 Yannuzzi LA. Type A behavior and central serous chorioretinopathy. Retina 1987;7:111-31.

9 Friedman M, Roseman RM. Association of specific overt behavior pattern with blood and cardiovascular findings. JAMA 1959;169:1286-96.

10 Barret-Connort E. Sex differences in coronary heart disease. Why are women so superior? The 1995 Ancel Keys Lecture. Circulation 1997:95:252-64.

11 Tittl MK, Spaide RF, Wong D, et al. Systemic findings associated with central serous chorioretinopathy. Am J Ophthalmol 1999:128:63-8.

12 Kitzmann AS, Pulido JS, Diehl NN, et al. The incidence of central serous chorioretinopathyin Olmsted County, Minnesota, 1980-2002. Ophthalmology 2008;115:169-73.

13 Haimovici R, Koh S, Gagnon DR, et al. Risk factors for central serous chorioretinopathy: a case-control study. Ophthalmology 2004;111:244-9.

14 Tsai DC, Huang CC, Chen SH, et al. Central serous chorioretinopathy and risk of ischemic stroke: a population-based cohort study. $\mathrm{Br}$ J Ophthalmol 2012;96:1484-8
15 Silvain J, Pena A, Vignalou JB, et al. FXIII-A Leu 34 genetic variant in premature coronary artery disease: a genotype-phenotype case control study. Thromb Haemost 2011:106:511-20.

16 Ernst $\mathrm{E}$, Resch KL. Fibrinogen as a cardiovascular risk factor: a meta-analysis and review of the literature. Ann Intern Med 1993:118:956-63.

17 Mills JD, Ariens RA, Mansfield MW, et al. Altered fibrin clot structure in the healthy relatives of patients with premature coronary artery disease. Circulation 2002;106:1938-42.

18 Yannuzzi LA. Central serous chorioretinopathy: a personal perspective. Am J Ophthalmol. 2010;149:361-3.

19 Caccavale A, Romanazzi F, Imparato $M$, et al. Central serous chorioretinopathy: a pathogenetic model. Clin Ophthalmol 2011:5:239-43.

20 Le D, Yannuzi LA, Spaide RF, et al. Subretinal exudative deposits in central serous chorioretinopathy. Br J Ophthalmol 1993;77:349-53.

21 Caccavale $A$, Romanazzi $F$, Imparato $M$, et al. Low-dose aspirin as treatment for central serous chorioretinopathy. Clin Ophthalmol 2010:4:899-903.

22 Caccavale A, Imparato M, Romanazzi $F$, et al. A new strategy of treatment with low-dosage acetyl salicylic acid in patients affected by central serous chorioretinopathy. Med Hypotheses 2009;73:435-7.

23 Chida Y, Hamer M. Chronic psychosocial factors and acute physiological responses to laboratory-induced stress in healthy population: a quantitative review of 30 years of investigations. Psychol Bull 2008;134:829-85.

24 Friedman HS, Booth-Kewley S. Personality type A behavior and coronary heart disease: the role of emotional expression. J Pers Soc Psychol 1987;153:783-92.

25 Malliani A, Montano N. Sympathetic overactivity in ischemic heart disease. Clin Sci 2004; 106:567-8

26 Tewari HK, Gadia R, Kumar D, et al. Sympathetic-parasympathetic activity and reactivity in central serous chorioretinopathy: a case-control study. Invest Ophthalmol Vis Sci 2006;47:3474-8.

27 Haimovici R, Rumelt S, Melby J. Endocrine abnormalities in patients with central serous chorioretinopathy. Ophthalmology 2003;110:698-703.

28 Van Zaane B, Nur E, Squizzato A, et al. Hypercoagulable state in Cushing's syndrome: a systematic review. J Clin Endocrinol Metab 2009;94:2743-50. 